\title{
Hot Corrosion Behaviour of Detonation Gun Sprayed Stellite-6 and Stellite-21 Coating on Boiler Steel SAE 431 at $900^{\circ} \mathrm{C}$
}

\author{
N. K. Mishra, ${ }^{1}$ A. K. Rai, ${ }^{1}$ S. B. Mishra, ${ }^{1}$ and R. Kumar ${ }^{2}$ \\ ${ }^{1}$ Department of Mechanical Engineering, Motilal Nehru National Institute of Technology Allahabad, Allahabad 211004, India \\ ${ }^{2}$ BBDNIIT, Lucknow 227105, India
}

Correspondence should be addressed to N. K. Mishra; nkm1676@yahoo.co.in

Received 18 February 2014; Revised 30 March 2014; Accepted 14 April 2014; Published 6 May 2014

Academic Editor: Flavio Deflorian

Copyright (C) 2014 N. K. Mishra et al. This is an open access article distributed under the Creative Commons Attribution License, which permits unrestricted use, distribution, and reproduction in any medium, provided the original work is properly cited.

\begin{abstract}
Hot corrosion is the serious problem in gas turbines, superheaters, and economizers of coal-fired boilers. It occurs due to the usage of wide range of fuels such as coal, oil, and so on at the elevated temperatures. Protective coatings on boiler steels are used under such environments. In the present investigation, Stellite- 6 and Stellite-21 coatings have been deposited on boiler steel SAE 431 by detonation gun method. The hot corrosion performance of Stellite- 6 and Stellite-21 coated as well as uncoated SAE 431 steel has been evaluated in aggressive environment of $\mathrm{Na}_{2} \mathrm{SO}_{4}-82 \% \mathrm{Fe}_{2}\left(\mathrm{SO}_{4}\right)_{3}$ under cyclic conditions at an elevated temperature of $900^{\circ} \mathrm{C}$ for total duration of 50 cycles. Thermogravimetric technique was used to approximate the kinetics of hot corrosion. Stellite- 6 coating imparted better hot corrosion resistance than Stellite-21 coating in the given environment. Scanning electron microscopy was used to characterize the surface of hot corrosion products.
\end{abstract}

\section{Introduction}

The degradation of the material at an unpredictably rapid rate is of great concern at high temperature in boilers, gas turbines, and industrial waste incinerators [1-4]. The use of residual fuel oil in energy generation systems is well known due to depletion of high-grade fuels and for economic reasons. Residual fuel oil contains sodium, vanadium, and sulphur as impurities. These impurities react together to form low melting point compounds, known as ash, which deposit on the surface of materials and induce hot corrosion [5]. There is a general agreement that condensed alkali metal salts such as $\mathrm{Na}_{2} \mathrm{SO}_{4}, \mathrm{~V}_{2} \mathrm{O}_{5}$, and $\mathrm{Fe}_{2}\left(\mathrm{SO}_{4}\right)_{3}$ are commonly found as hot corrosion promoter in these applications. Due to high cost of removing these impurities, the use of low grade fuels is usually justified [6]. The gaseous environments of these salts may cause rapid material degradation and result in premature failure of components due to their corrosive nature [4]. Hot corrosion resistance of the materials used in the high-temperature regions can be improved by the application of protective thermal spray coating since it alters the surface without affecting the bulk material properties [7$10]$. Detonation gun is one of the thermal spray processes used to produce coatings having extremely good adhesive strength with low porosity and higher density [11-13]. The objective of the present work is to investigate the role of detonation gun spray method on the hot corrosion resistance of Stellite- 6 and Stellite-21 coatings on SAE 431 boiler steel. Hot corrosion tests of specimens were carried out in the molten salt environment $\mathrm{Na}_{2} \mathrm{SO}_{4}-82 \% \mathrm{Fe}_{2}\left(\mathrm{SO}_{4}\right)_{3}$ at $900^{\circ} \mathrm{C}$ for 50 cycles of one hour duration. Thermogravimetric technique was used to study the hot corrosion behaviour of Stellite- 6 and Stellite-21 coatings as well as bare SAE 431 boiler steel. Surface SEM analysis is used to characterize the surfaces of hot corrosion products.

\section{Experimental Procedure}

\subsection{Coating Development}

2.1.1. Substrate Material, Coating Powders. SAE 431 boiler steel (C-0.16, Mg-1.0, Si-1, S-0.03, P-0.04, Cr-16, Ni-2.5, Fe-Bal.) is selected as substrate material. The specimens measuring approximately $20 \mathrm{~mm} \times 15 \mathrm{~mm} \times 5 \mathrm{~mm}$ were cut and polished by using 180, 220, 320, 400, and 600 grades of $\mathrm{SiC}$ emery papers. 
TABLE 1: Parameters used in detonation gun spray.

\begin{tabular}{lc}
\hline Parameters & Stellite-6/-21 coating \\
\hline Oxygen flow rate $\left(\mathrm{O}_{2}\right)$ & $3120 \mathrm{SLPH}$ \\
Pressure & $0.2 \mathrm{MPa}$ \\
Acetylene flow rate $\left(\mathrm{C}_{2} \mathrm{H}_{2}\right)$ & $2400 \mathrm{SLPH}$ \\
Pressure & $0.14 \mathrm{MPa}$ \\
Nitrogen flow rate $\left(\mathrm{N}_{2}\right)$ & $1040 \mathrm{SLPH}$ \\
Pressure & $0.4 \mathrm{MPa}$ \\
Spray angle & $90^{\circ}$ \\
Spray distance & $180 \mathrm{~mm}$ \\
Power & $450 \mathrm{VA}$ \\
Fire rate & $1-10 \mathrm{~Hz}$ \\
Coating thickness (average) & $250 \mu \mathrm{m}$ \\
Gun internal diameter & $22 \mathrm{~mm}$ \\
Length of gun & $1.5 \mathrm{~m}$ \\
Position of powder injector & $90^{\circ}$ to the sample \\
Particle velocity & $600-900 \mathrm{~m} / \mathrm{s}$ \\
Temperature of plasma & $3900^{\circ} \mathrm{C}$ \\
\hline
\end{tabular}

The specimens were blasted using Stellite- 6 and Stellite21 (grit 20) powders prior to deposition of coating. Commercially available Stellite-6 (C-1.05, W-4.48, Ni-1.95, Fe-1.78, Cr29.50, Si-1.18, Mg-0.45, Co-Bal.) and Stellite-21 (C-0.25, Mo5.5, Ni-3.0, Fe-1.0, Cr-29.0, Si-1.0, Co-Bal.) powders were used as the coating powders.

2.1.2. Coating Deposition. Detonation gun method was used to apply the coatings of Stellite- 6 and Stellite- 21 on the boiler steel substrate at SVX Powder M Surface Engineering Pvt. Ltd., Greater Noida (India). The process parameters used in the present work are reported in Table 1 . Nitrogen plays an important role in the gas mixture. The role of nitrogen is to flush the chamber as all the remaining hot powder particles can otherwise detonate the explosive mixture in an irregular fashion and render the whole process uncontrollable.

2.2. Hot Corrosion Test. All the samples were washed in acetone for removing any dirt and moisture from the surface. The specimens were heated in an oven to about $250^{\circ} \mathrm{C}$ for proper adhesion of the salt layer. $A$ salt of $\mathrm{Na}_{2} \mathrm{SO}_{4}-82 \% \mathrm{Fe}_{2}\left(\mathrm{SO}_{4}\right)_{3}$ thoroughly mixed with distilled water was applied uniformly on the warm polished specimens with the help of a camel hair brush. The amount of salt layer was kept in the range of 4.0$5.0 \mathrm{mg} / \mathrm{cm}^{2}$. The salt coated specimens were dried by keeping them in the oven at $100^{\circ} \mathrm{C}$ for 3-4 hours. Hot corrosion studies were performed in a molten salt $\mathrm{Na}_{2} \mathrm{SO}_{4}-82 \% \mathrm{Fe}_{2}\left(\mathrm{SO}_{4}\right)_{3}$ for 50 cycles under cyclic conditions. Each cycle consisted of 1 hour heating the alumina boats with specimens at $900^{\circ} \mathrm{C}$ in a Kanthal wire tube furnace followed by 20 minutes cooling at room temperature. During hot corrosion runs, the weights of specimens and boats were measured together at the start and end of each cycle with the help of electronic weighing balance with an accuracy of $1 \mathrm{mg}$. The spalled scale was also included at the time of measurements of weight. The corrosion rate was calculated using the weight change measurements of the

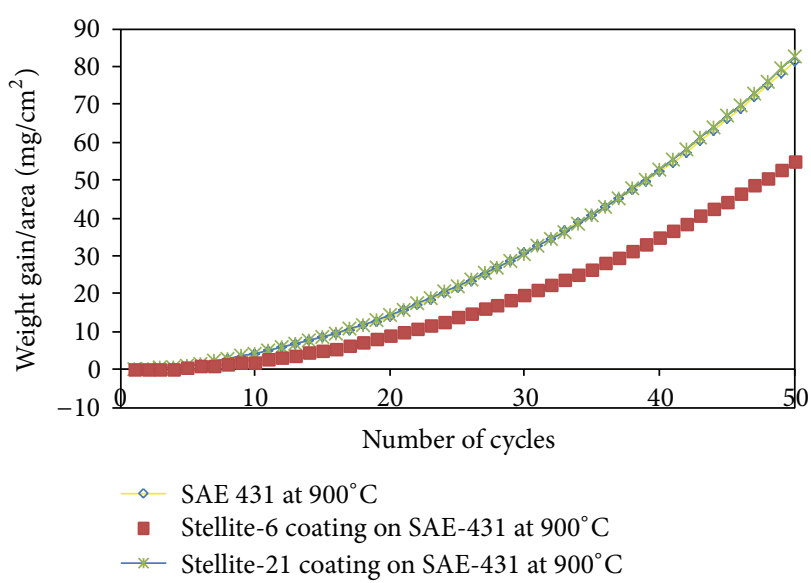

FIGURE 1: Weight gain per unit area versus number of cycles plots for Stellite- 6 and Stellite-21 coated and uncoated SAE 431 boiler steel after hot corrosion at $900^{\circ} \mathrm{C}$ under $\mathrm{Na}_{2} \mathrm{SO}_{4}-82 \% \mathrm{Fe}_{2}\left(\mathrm{SO}_{4}\right)_{3}$ environment for 50 cycles.

uncoated and coated steel samples. The surfaces of all the samples after corrosion tests were analysed using scanning electron microscope (Zeiss SEMEVO 18).

\section{Results and Discussion}

All the as-sprayed samples were polished to similar condition before hot corrosion test. The average surface roughness ( $\mathrm{Ra})$ of the polished coating was found in the range of $1-4 \mu \mathrm{m}$. The porosity of the as-sprayed coating was found to be in the range of 0.1 to $1 \%$.

3.1. Cyclic Hot Corrosion in Molten Salt. Figure 1 shows the weight gain per unit area for the SAE 431 boiler steel, Stellite6 , and Stellite-21 coatings after hot corrosion in the presence of molten salt $\mathrm{Na}_{2} \mathrm{SO}_{4}-82 \% \mathrm{Fe}_{2}\left(\mathrm{SO}_{4}\right)_{3}$ environment under cyclic conditions. The lowest weight gain value was observed for Stellite- 6 coating followed by SAE 431 boiler steel and Stellite-21 coating under the tested environment. Stellite-21 coated and bare SAE 431 boiler steel have shown almost similar weight gains. During the initial 10 cycles, weight gains of coated and uncoated samples were almost negligible. The overall weight gains after 50 cycles for SAE 431 steel, Stellite21 coating, and Stellite- 6 coating were found to be 81.440 , 82.556 , and $54.812 \mathrm{mg} / \mathrm{cm}^{2}$, respectively.

The weight gain square $\left(\mathrm{mg}^{2} / \mathrm{cm}^{4}\right.$ ) versus time (number of cycles) plots are plotted in Figure 2 to establish the rate law for the hot corrosion. It can be seen from the graph that the coatings follow a nearly parabolic rate law.

The parabolic rate constant $K_{p}$ was calculated using a linear least-square algorithm to a function in the form of $(W / A)^{2}=K_{p} t$, where $W / A$ is the weight gain per unit surface area $\left(\mathrm{mg} / \mathrm{cm}^{2}\right)$ and $t$ is time of exposure in hours [14]. The values of parabolic rate constant $K_{p}$ are found to be 111.41, 114, and $50.20 \times 10^{-8} \mathrm{~g}^{2} \mathrm{~cm}^{-4} \mathrm{~s}^{-1}$ for SAE 431 boiler steel, Stellite21 coating, and Stellite- 6 coating, respectively. 


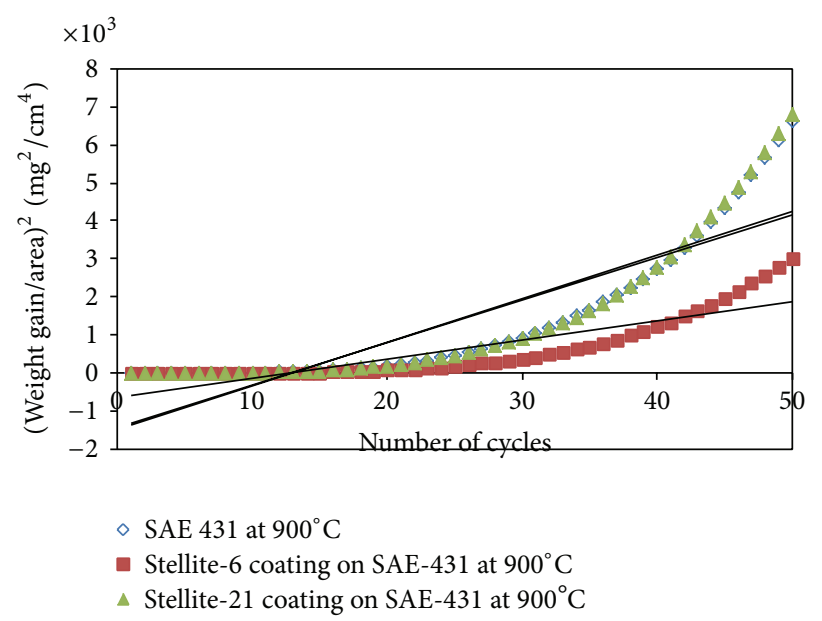

FIGURE 2: Square of cumulative weight gain per unit area against number of cycles plots for uncoated and Stellite-6 and Stellite-21 coated SAE 431 boiler steel subjected to hot corrosion under $\mathrm{Na}_{2} \mathrm{SO}_{4}-82 \% \mathrm{Fe}_{2}\left(\mathrm{SO}_{4}\right)_{3}$ environment at $900^{\circ} \mathrm{C}$ for 50 cycles.

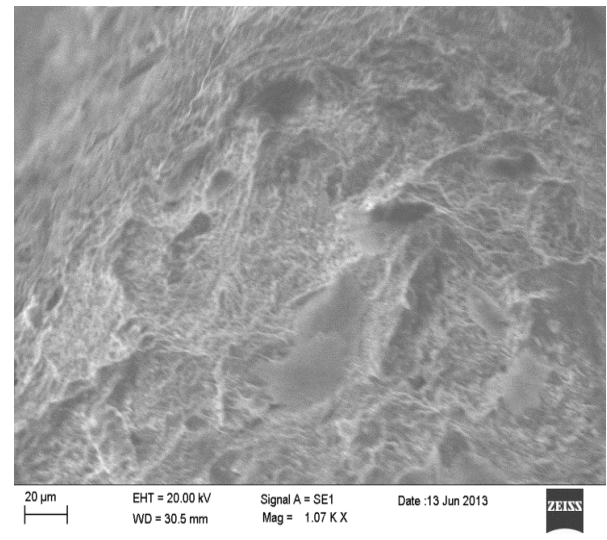

(a)

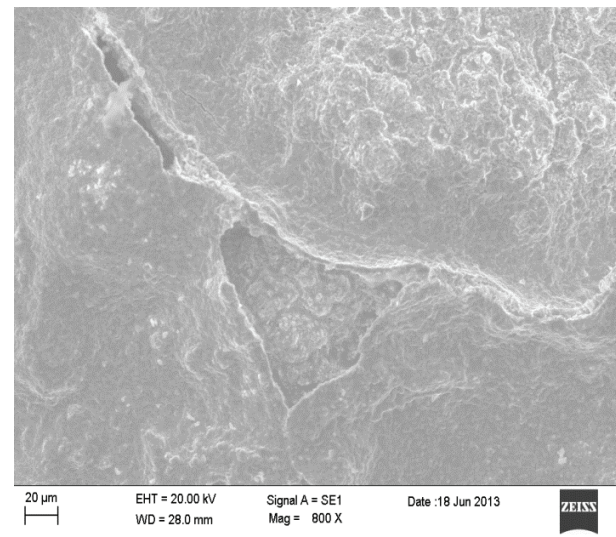

(b)

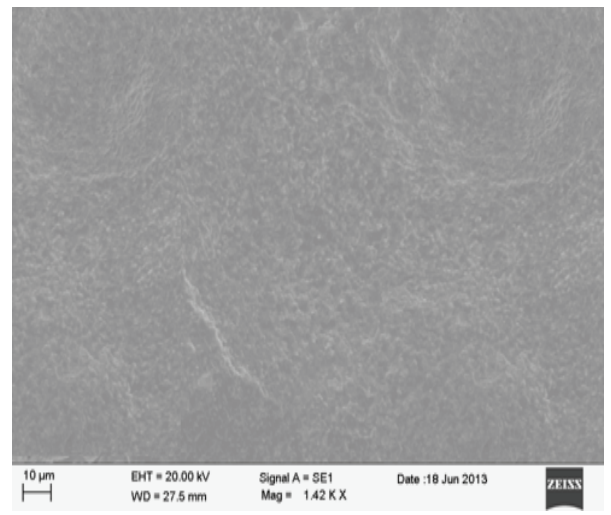

(c)

FIGURE 3: SEM micrographs of (a) SAE 431 boiler steel, (b) Stellite-21 coated SAE 431 boiler steel, and (c) Stellite-6 coated SAE 431 boiler steel subjected to $\mathrm{Na}_{2} \mathrm{SO}_{4}-82 \% \mathrm{Fe}_{2}\left(\mathrm{SO}_{4}\right)_{3}$ at $900^{\circ} \mathrm{C}$ for 50 cycles.

3.2. SEM Analysis. Figure 3 shows the SEM micrographs of SAE- 431 boiler steel and Stellite- 6 and Stellite-21 coatings after exposure to hot corrosion environment for 50 cycles. Figure 3(a) reveals that the surface of boiler steel is distorted and rough. No cracks are visible on the surface of boiler steel. In case of Stellite-21 coating, surface cracks can be seen from the SEM image of the surface (Figure 3(b)). Uncoated and Stellite-21 coated boiler steel have shown almost similar weight gain, marginally higher by Stellite- 21 coating than by SAE 431 boiler steel. The microcrack originated from the edge 
and forwarded towards the centre of Stellite-21 coating might have contributed to the spallations and higher weight loss of the coating. The SEM image of Stellite- 6 coating seems to be smooth and well adherent on the substrate (Figure 3(c)). Stellite- 6 coating has shown the lowest hot corrosion rate among the tested materials. According to Sidhu et al. (2007), Stellite- 6 coating has a tendency to act like a diffusion barrier to the degrading species [15]. They further reported the formation of oxides of chromium and silicon at the boundaries of Co-rich splats. According to Luthra [16] and Luthra and Wood [17] the increase in the growth of $\mathrm{CoCr}_{2} \mathrm{O}_{4}$ and $\mathrm{Cr}_{3} \mathrm{O}_{4}$ formation increases the corrosion resistance of Stellite- 6 coating. The diffusion activities through the $\mathrm{CoO}$ may have been blocked due to the formation of $\mathrm{CoCr}_{2} \mathrm{O}_{4}$, thus suppressing the further formation of this oxide $(\mathrm{CoO})$ $[16,17]$. Sidhu and Prakash [18] have also reported the formation of similar phases while studying the plasma sprayed Stellite- 6 coating under $\mathrm{Na}_{2} \mathrm{SO}_{4}-60 \% \mathrm{~V}_{2} \mathrm{O}_{5}$ environment.

\section{Conclusions}

In the present work, hot corrosion behaviour of detonation gun sprayed Stellite- 6 and Stellite- 21 coatings on SAE 431 boiler steel in aggressive environment of $\mathrm{Na}_{2} \mathrm{SO}_{4}+$ $82 \% \mathrm{Fe}_{2}\left(\mathrm{SO}_{4}\right)_{3}$ at $900^{\circ} \mathrm{C}$ has been investigated and the following conclusions are made.

All the samples show negligible weight gain during initial 10 cycles of exposure and thereafter the weight gain gradually increases. Stellite- 6 coating has shown the lowest weight gain among the tested materials under hot corrosion environment. Uncoated and stellite-21 coated SAE 431 boiler steel have shown almost similar weight gains. Higher weight gain in case of Stellite-21 coating might be due to the initiation of cracks from the edges.

\section{Conflict of Interests}

The authors declare that there is no conflict of interests regarding the publication of this paper.

\section{References}

[1] N. Eliaz, G. Shemesh, and R. M. Latanision, "Hot corrosion in gas turbine components," Engineering Failure Analysis, vol. 9, no. 1, pp. 31-43, 2002.

[2] V. H. Hidalgo, F. J. B. Varela, A. C. Menéndez, and S. P. Martínez, "A comparative study of high-temperature erosion wear of plasma-sprayed $\mathrm{NiCrBSiFe}$ and $\mathrm{WC}-\mathrm{NiCrBSiFe}$ coatings under simulated coal-fired boiler conditions," Tribology International, vol. 34, no. 3, pp. 161-169, 2001.

[3] N. K. Mishra, N. Kumar, and S. B. Mishra, "Hot corrosion behaviour of detonation gun sprayed $\mathrm{Al}_{2} \mathrm{O}_{3}-40 \mathrm{TiO}_{2}$ coating on nickel based superalloys at $900^{\circ} \mathrm{C}$," Indian Journal of Materials Science, vol. 2014, Article ID 453607, 5 pages, 2014.

[4] D. Wang, "Corrosion behavior of chromized and/or aluminized 2.25Cr-1Mo steel in medium-BTU coal gasifier environments," Surface and Coatings Technology, vol. 36, no. 1-2, pp. 49-60, 1988.
[5] T. S. Sidhu, A. Malik, S. Prakash, and R. D. Agrawal, "Oxidation and hot corrosion resistance of HVOF WC-NiCrFeSiB coating on Ni- and Fe-based superalloys at $800^{\circ} \mathrm{C}$," Journal of Thermal Spray Technology, vol. 16, no. 5-6, pp. 844-849, 2007.

[6] A. M. Beltran and T. N. Shores, "Hot corrosion," in The Superalloys, C. T. Sims and W. C. Hagel, Eds., chapter 11, John Wiley \& Sons, New York, NY, USA, 1988.

[7] T. Sundararajan, S. Kuroda, T. Itagaki, and F. Abe, "Steam oxidation resistance of $\mathrm{Ni}-\mathrm{Cr}$ thermal spray coatings on $9 \mathrm{Cr}$ 1Mo steel. Part 1: 80Ni-20Cr," ISIJ International, vol. 43, no. 1, pp. 95-103, 2003.

[8] T. Sundararajan, S. Kuroda, and F. Abe, "Steam oxidation studies on $50 \mathrm{Ni}-50 \mathrm{Cr} \mathrm{HVOF}$ coatings on $9 \mathrm{Cr}-1 \mathrm{Mo}$ steel: change in structure and morphology across the coating/substrate interface," Materials Transactions, vol. 45, no. 4, pp. 1299-1305, 2004.

[9] Y. Matsubara and A. Tomiguchi, "Surface texture and adhesive strength of high velocity oxy-fuel sprayed coatings for rolls of steel mills," in Thermal Spray: International Advances in Coatings Technology: Proceedings of the International Thermal Spray Conference, 28 May-5 June 2 1992, Orlando, Florida USA, C. C. Berndt, Ed., pp. 637-645, 1992.

[10] L. Byrnes and M. Kramer, "Method and apparatus for the application of thermal spray coatings on aluminium engine cylinder bores," in Proceedings of the 7th National Thermal Spray Conference, pp. 39-42, Boston, Mass, USA, 1994.

[11] V. Chawla, B. S. Sidhu, D. Puri, and S. Prakash, "Performance of plasma sprayed nanostructured and conventional coatings," Journal of the Australian Ceramic Society, vol. 44, no. 2, pp. 5662, 2008

[12] P. S. Sidky and M. G. Hocking, "Review of inorganic coatings and coating processes for reducing wear and corrosion," British Corrosion Journal, vol. 34, no. 3, pp. 171-183, 1999.

[13] B. S. Sidhu, D. Puri, and S. Prakash, "Mechanical and metallurgical properties of plasma sprayed and laser remelted $\mathrm{Ni}$ $20 \mathrm{Cr}$ and Stellite-6 coatings," Journal of Materials Processing Technology, vol. 159, no. 3, pp. 347-355, 2005.

[14] Z. Znamirowski, L. Pawlowski, T. Cichy, and W. Czarczynski, "Low macroscopic field electron emission from surface of plasma sprayed and laser engraved $\mathrm{TiO}_{2}, \mathrm{Al}_{2} \mathrm{O}_{3}+13 \mathrm{TiO}_{2}$ and $\mathrm{Al}_{2} \mathrm{O}_{3}+40 \mathrm{TiO}_{2}$ coatings," Surface and Coatings Technology, vol. 187, no. 1, pp. 37-46, 2004.

[15] T. S. Sidhu, S. Prakash, and R. D. Agrawal, "A comparative study of hot corrosion resistance of HVOF sprayed $\mathrm{NiCrBSi}$ and Stellite- 6 coated Ni-based superalloy at $900^{\circ} \mathrm{C}$," Materials Science and Engineering A, vol. 445-446, pp. 210-218, 2007.

[16] K. L. Luthra, "Kinetics of low temperature hot corrosion of CoCr-Al alloys," Journal of the Electrochemical Society, vol. 132, no. 6, pp. 1293-1298, 1985.

[17] K. L. Luthra and J. H. Wood, "High chromium cobalt-base coatings for low temperature hot corrosion," Thin Solid Films, vol. 119, no. 3, pp. 271-280, 1984.

[18] B. S. Sidhu and S. Prakash, "Studies on the behaviour of stellite6 as plasma sprayed and laser remelted coatings in molten salt environment at $900^{\circ} \mathrm{C}$ under cyclic conditions," Journal of Materials Processing Technology, vol. 172, no. 1, pp. 52-63, 2006. 

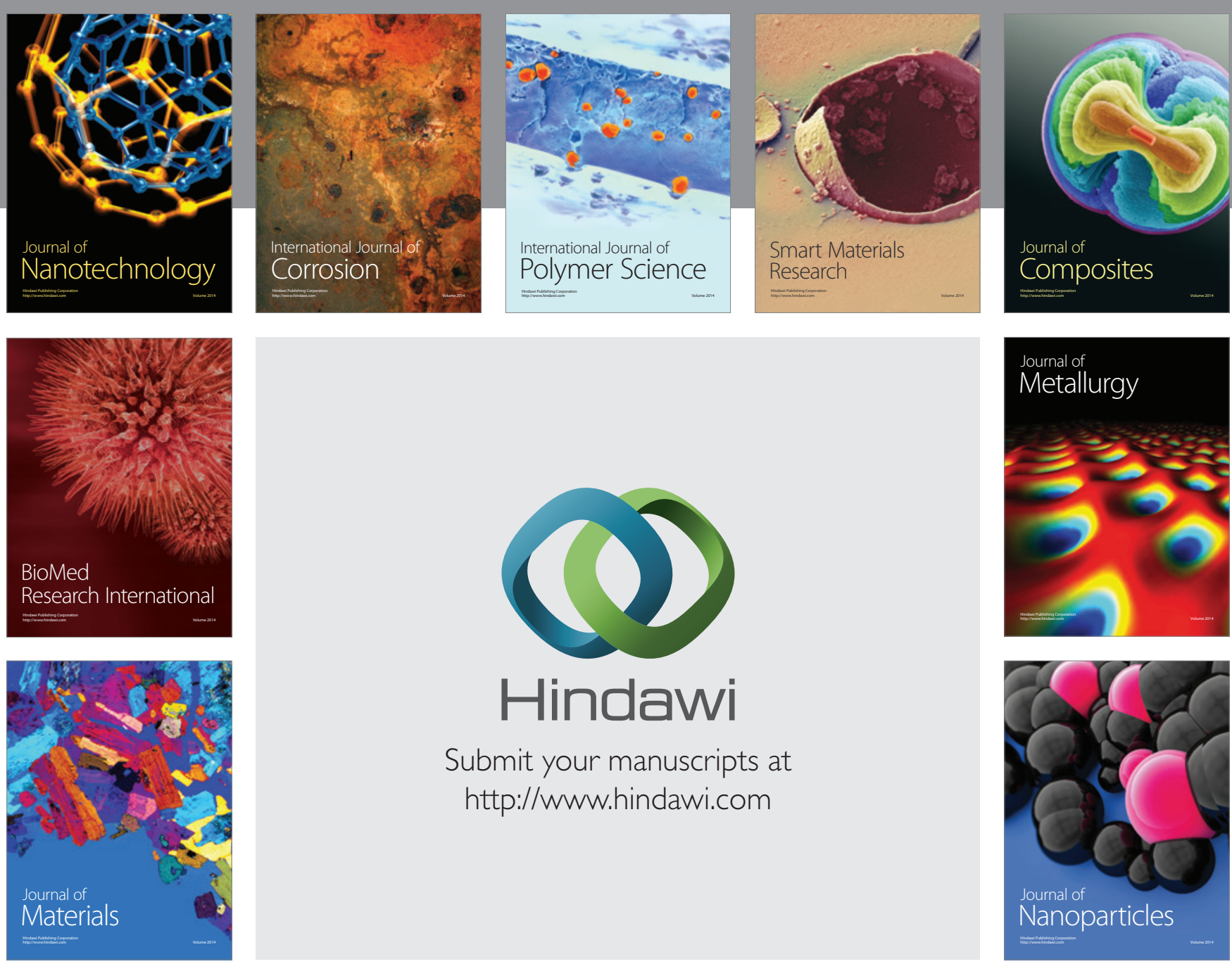

Submit your manuscripts at http://www.hindawi.com
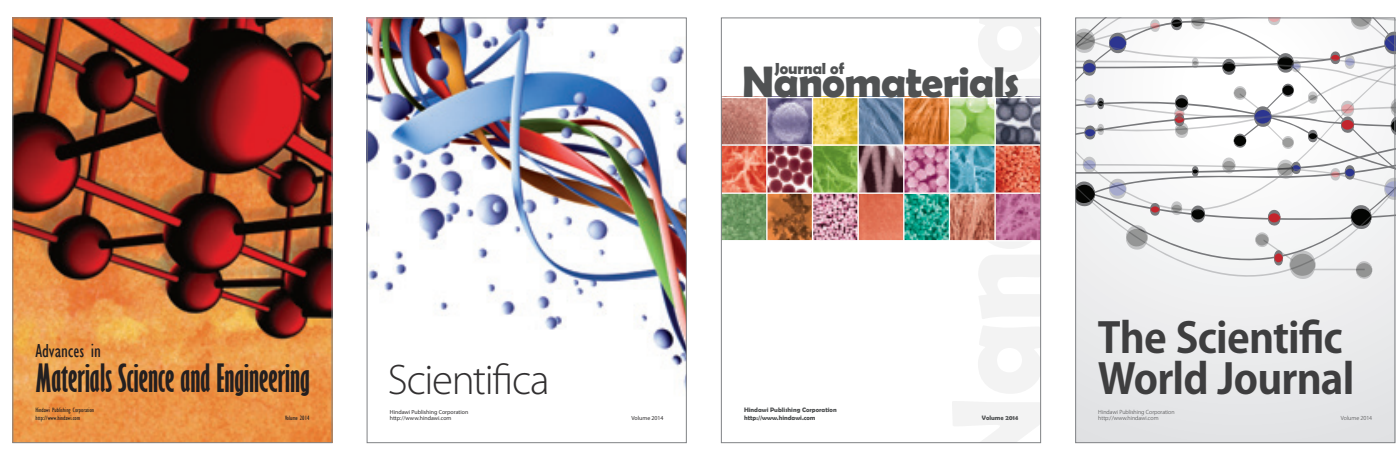

\section{The Scientific World Journal}
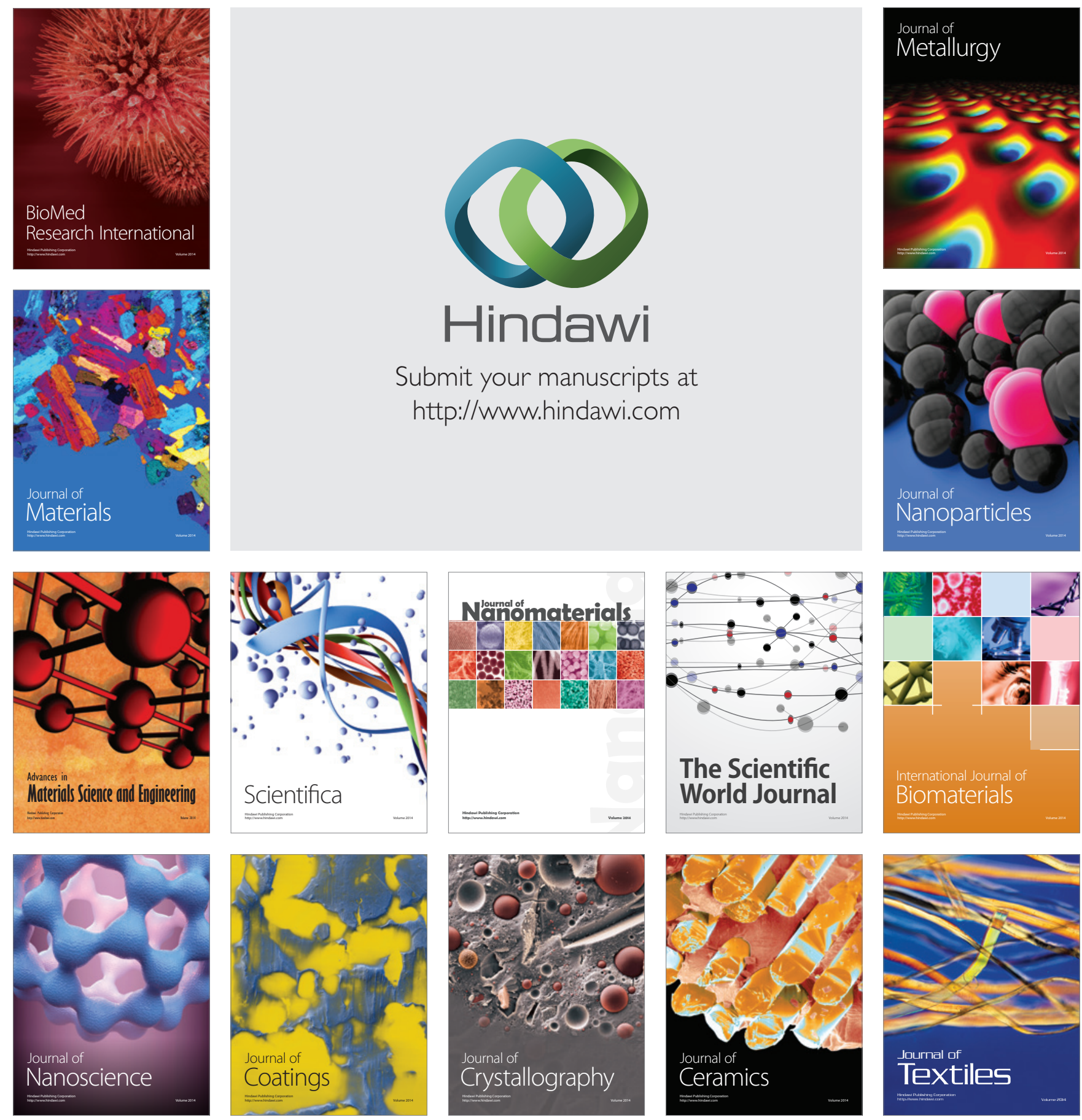